\title{
Dynamic response of low frequency Profiled Steel Sheet Dry Board (PSSDB) floor system
}

\section{Abstract}

Slender structural floors could experience irritating vibration problems due to human walking load and so, vibration acceptability of such floors is an essential subject in addition to the usual strength criterion. This paper focuses on the dynamic response of a lightweight composite structural system known as Profiled Steel Sheet Dry Board (PSSDB) to evaluate its vibration acceptability under human walking load. For this point, twelve (12) PSSDB panels in the category of Low Frequency Floor (LFF) were developed via Finite Element Method (FEM). The natural frequencies and mode shapes of the studied panels were determined based on the developed finite element models. For more realistic evaluation on dynamic response of the panels, dynamic load models representing human walking load were considered based on their Fundamental Natural Frequency (FNF), and also time and space description. The peak accelerations of the studied panels were determined and then compared to the limiting value proposed by the standard code of ISO 2631-2. Effects of changing thickness of the Profiled Steel Sheet (PSS) and Dry Board (DB), screw spacing, damping ratio, type of support, and floor span on the dynamic responses of the PSSDB panels were evaluated. According to literature, effect of presence of concrete on the dynamic response of the PSSDB system was revealed. The results demonstrated that although some factors reduced dynamic response of the PSSDB system under human walking load, low frequency PSSDB floor system could reach high vibration levels resulting in lack of comfortableness for users.

\section{Keywords}

PSSDB, low frequency floor, vibration acceptability, human walking load

\section{Farhad Abbas Gandomkar*,} Wan Hamidon Wan Badruzzaman, Siti Aminah Osman, Imiruddin Ismail

Department of Civil \& Structural Engineering, Faculty of Engineering \& Built Environment, Universiti Kebangsaan Malaysia, 43600 Bangi, Selangor, Malaysia

Tel: 0060-3-89255760,

Fax: 0060-3-89255703.

Received 10 Sep 2012

In revised form 24 Jan 2013

*Author email:

Email: farhad.abbas.gandomkar@gmail.com 


\section{INTRODUCTION}

Serviceability in modern structures constructed by high strength and lightweight materials is the most critical issue and should be considered in addition to the strength/safety criteria [1,2]. In this case, generally codes and standards present two approaches to evaluate serviceability of floors. First is static deflection caused by nominal live load which is commonly limited to SPAN/360 (A58, 1982) or between SPAN/180 and SPAN/480 in different specifications (ACI 318-77, 1977 and AISC, 1978) and second is the minimum of DEPTH/SPAN for flexural members depending on the end restrains (ACI 318-77, 1977) [3]. Ellingwood and Tallin [3] stated that control of the static deflection is not sufficient to evaluate the vibration serviceability of floors. On the other hand, Al-Foqaha et al. [4] reported a number of researchers (Onysko (1970, 1985, 1988); Polensek (1970, 1971, 1975, 1988); Polensek et al. (1976); Allen (1974, 1990); Allen and Rainer (1976); Allen and Murray 1993; Murray 1979; Chui 1986; Smith and Chui 1988; Ebrahimpour and Sack 1989; Ohlsson (1988, 1991); Kalkert et al. (1993); Dolan et al. (1995), Lenzen (1966); Wiss and Parmelee (1974), Filiatrault et al. (1990); Foschi et al. (1995); Kalkert et al. (1995)) has declared that evaluation of the floor vibration serviceability may not be performed by control of the static deflection such as SPAN/360 [4]. Wood floor systems were investigated based on the finite element method under dynamic loads induced by human activities. A series of design curves related to root-mean-square (RMS) acceleration, mass, and FNF were proposed and compared with the experimental study which resulted in a close agreement. It was concluded that the vibration criteria based on static properties or FNF are not enough to prevent unwanted vibration of floors [4].

The international standards organization [5] recommended an acceleration limit as a baseline in terms of RMS for various applications of floors, as illustrated in Fig. 1. This Standard proposed a criterion based on the peak acceleration by multiplication of baseline with 10 for offices, 30 for shopping malls and indoor footbridges, and 100 for outdoor footbridges.

Latin American Journal of Solids and Structures 10(2013) $1135-1154$ 


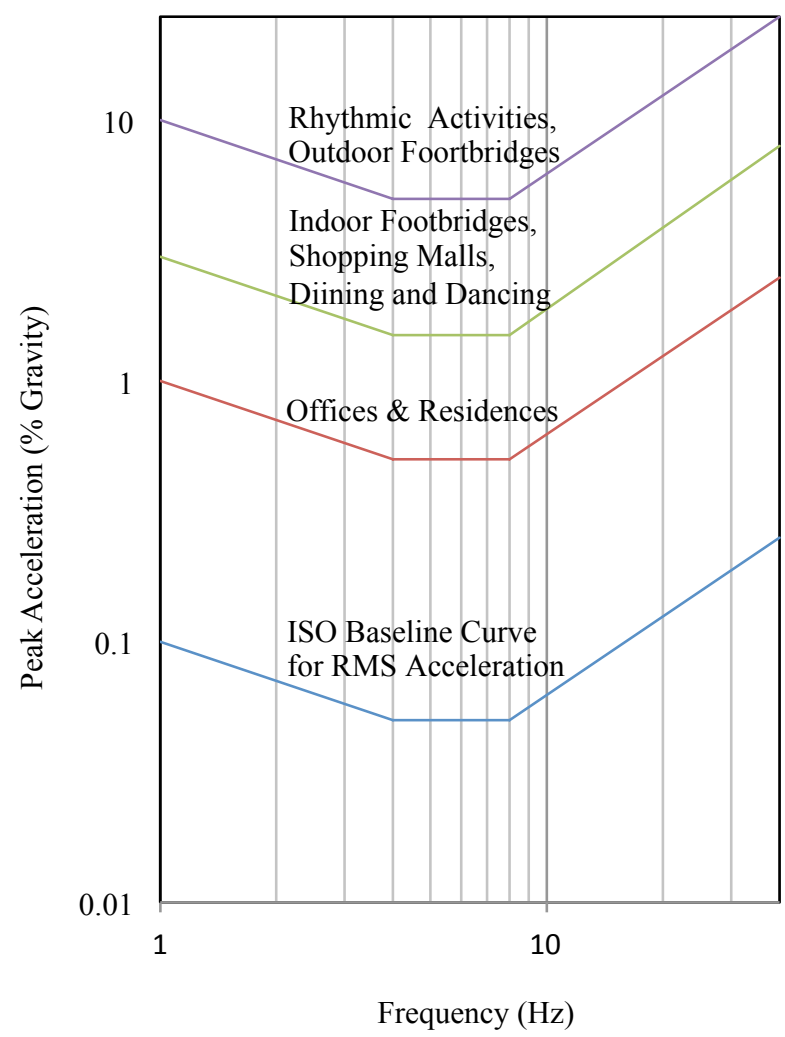

Figure 1 Recommended peak acceleration for human comfort for vibrations due to human activities (ISO 2631-2 1989).

The American institute of steel and construction [6] has proposed criteria for human comfort which are the same as the ISO Standard [5], as shown in Fig. 1.

A number of authors have evaluated the vibration serviceability of floors under human activities through determination of their dynamic responses, analysis and experiments from few years ago [7]. Sandun de Silva and Thambiratnam [8], da Silve et al. [9], da Silve et al. [10], El-Dardiry and Ji [11], Williams and Waldron [12], and Chen [2] determined dynamic responses of composite floors under human activities to obtain their vibration serviceability. Ellingwood and Tallin [3] mathematically studied the dynamic response of floors under a pragmatic model instead of the pedestrian dynamic load. An experimental serviceability criterion was also presented to minimize the vibration of the floors. Smith and Chui [13] presented a usable method for designers based on a flow chart to evaluate the dynamic response of lightweight wood-joist floors by determination of natural frequency and RMS acceleration of the system under the heel-drop impact load. Howard and Hansen [14] investigated the vibration analysis of waffle floors based on a mathematical method for several manufacturing buildings which was also verified by finite element and experimental results. Foschi et al. [15] presented an experimental and analytical study on the vibration response of wood floors as a lightweight panel useful in residential and commercial buildings under the impact load induced by users. Occupants were modeled by two simple oscillators, one degree of freedom and two degrees of freedom. Osborne and Ellis [16] presented a study on a long-span lightweight LFF (FNF lower than $10 \mathrm{~Hz}$ [17]) system by analyzing various methods to evaluate the vibration acceptability of the system through obtaining FNF, damping ratio and acceleration. Willford et al. [18] reviewed five 
methods to predict the response of structures under the footfall load. The study was conducted in two parts; floor and bridge with the FNF lower than $10 \mathrm{~Hz}$, and also floor with the FNF above 10 $\mathrm{Hz}$ (HFF). Mello et al. [7] also studied the dynamic analysis of a composite system made of concrete slab and steel beams. The research on acceptability of studied models was performed under four types of dynamic loads which were represented by human walking load, measurement of peak acceleration of panels, and comparison with limit of codes. The dynamic response of the mentioned floors was investigated by using FEM as a modern computational tool for structural analysis.

The PSSDB is a lightweight composite structural system consisting of the PSS and DB attached together by self-drilling and self-tapping screws, as illustrated in Fig. 2.

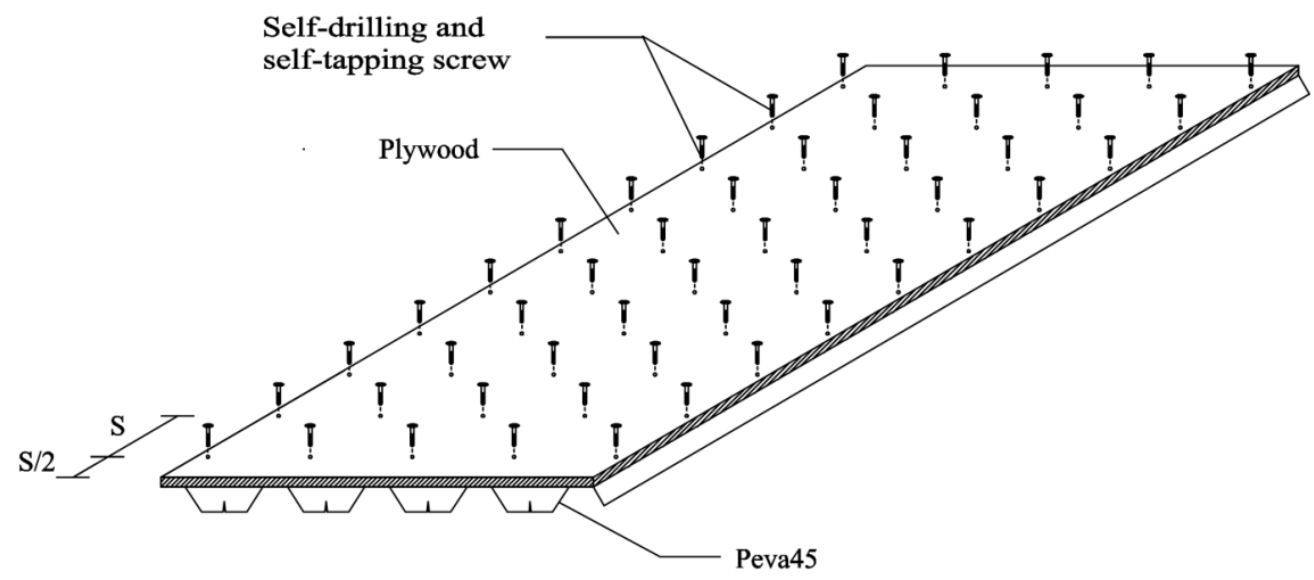

Figure 2 Profiled steel sheet dry board system.

The PSSDB with in-filled concrete is called PSSDBC. Gandomkar et al. [19] determined dynamic response of the PSSDBC panels with various conditions under human walking load to evaluate their comfortableness. It was reported that since the PSSDB system is slender and flexible in its nature, the natural frequency of the floor system may be low and becomes perceivable to users [20]. In addition, Gandomkar et al. [21] revealed experimentally and numerically that the PSSDB system with practical spans is in the category of LFF. Accordingly, the PSSSB system with the practical span is exposed to vibrations of human activities, because their FNF may be close to the frequency range of human activities. Therefore, a consistent dynamic analysis of the PSSDB system with the practical span is advisable to evaluate the vibration serviceability of the system under human walking activities.

This paper investigates the dynamic response of the low frequency PSSDB floor system used as offices and residences under human walking load, with the same aspect like the work of Gandomkar et al. [19]. Twelve PSSDB panels were considered to illustrate effects of different parameters such as boundary conditions, damping ratio, thicknesses of the PSS and DB, screw spacing, and floor span on the dynamic responses of the studied panels. In addition, according to results of this study and research of Gandomkar et al. [19], effect of presence of concrete on the dynamic response of the PSSDB system was demonstrated. Firstly, natural frequencies and vibration modes of all panels were obtained. Secondly, dynamic responses of the studied panels in terms of peak acceleration were 
obtained and compared to the limiting values proposed by ISO 2631-2 [5], to reveal the vibration acceptability of the panels.

\section{HUMAN-INDUCED DYNAMIC LOADS}

Vibration of floors under human rhythmic activities is a very complex problem with respect to the mathematical or physical characterization of this phenomenon because the characteristics of dynamic excitation of these activities are interconnected to the individual body adversities and the ways which human performs a certain rhythmic activity [7]. Various studies tried to evaluate and model the dynamic loads of human activities. According to Mello et al. [7], the first pioneer for determination of the forces induced by human motion was Otto Fischer, a German mathematician, who presented his study in 1895. Also, Ohmart presented walk motion forces graphically in 1968. Folz and Foschi [22] idealized the occupants on the floor as lumped parameter model which are components of discrete masses, springs, and viscous dashpots with two and eleven degrees of freedom. Racic et al. [23] reviewed 271 references which deal with various experimental and analytical characterizations of human walking forces and their application in vibration serviceability design of civil engineering structures when subjected to pedestrian movement such as footbridges, floors and staircases. Mello et al. [7] reported that an experimental study was performed by Alves (1997) and Faisca (2003) on two kinds of concrete platforms; rigid and flexible, when a group of volunteers acted on them. The aim of their study was a description of forces induced by human activities such as; soccer and rock, aerobics, and jumps.

In the present study, dynamic responses of the studied panels were determined under following four dynamic human walking loads [7] to evaluate their vibration acceptability.

\subsection{First load model}

First load model which represents walking of people is shown in Eq. (1).

$$
F(t)=P \alpha_{i} \cos \left(2 \pi i f_{s} t\right)
$$

Where:

$P$ : individual's weight, taken as $700-800 \mathrm{~N}$;

$\alpha_{i}$ : dynamic coefficient for the $i$ th harmonic force component;

$i$ : harmonic multiple of the step frequency;

$f_{s}$ : step frequency;

$t$ : time in seconds.

In this load model, only one resonant harmonic of the load was considered. The harmonic multiple of the step frequency was adopted from Table 1 which depends on the FNF of the panel. For example, if calculated FNF of a panel was equal to $8.359 \mathrm{~Hz}$ (Panel Number (PN) of $8=$ PN8), according to Table 1, only fourth harmonic of the walking loads with the step frequency of $f_{s}=2.0897 \mathrm{~Hz}(4 \times 2.0897 \mathrm{~Hz}=8.359 \mathrm{~Hz})$ should be used in Eq. (1) to determine the first ap- 
plied load on the panel. Fig. 3 shows the first dynamic load model for the panel with FNF of equal to $8.359 \mathrm{~Hz}$.

Table 1 Loading frequencies, dynamic coefficients, and harmonic phase angles.

\begin{tabular}{ccccc}
\hline & \multicolumn{4}{c}{ Person walking } \\
\cline { 2 - 5 } $\begin{array}{c}\text { Harmonic } \\
\mathrm{i}\end{array}$ & $i f_{s}(\mathrm{~Hz})$ & $\alpha_{i}$ & \multicolumn{2}{c}{$\Phi$} \\
\cline { 3 - 5 } & & & $\begin{array}{c}\text { Second and third load } \\
\text { model }\end{array}$ & $\begin{array}{c}\text { Fourth load } \\
\text { model }\end{array}$ \\
\hline 1 & $1.6-2.2$ & 0.5 & 0 & 0 \\
2 & $3.2-4.4$ & 0.2 & $\pi / 2$ & $\pi / 2$ \\
3 & $4.8-6.6$ & 0.1 & $\pi / 2$ & $\pi$ \\
4 & $6.4-8.8$ & 0.05 & $\pi / 2$ & $3 \pi / 2$ \\
\hline
\end{tabular}

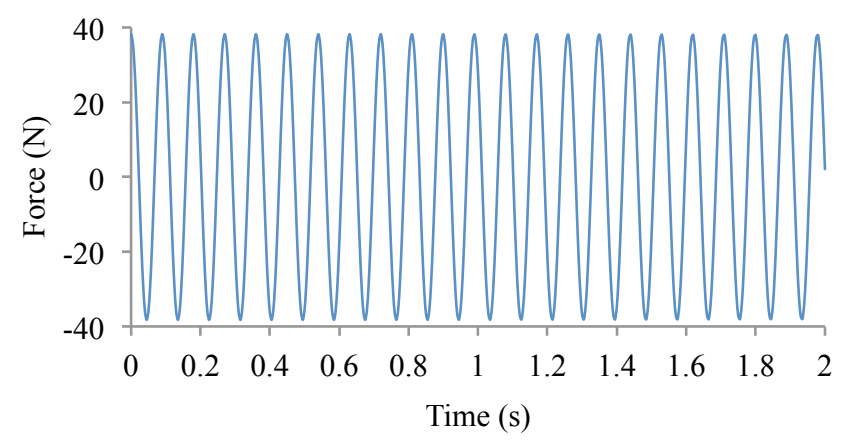

Figure 3 First load model for PN8.

\subsection{Second load model}

The second load model representing human walking load is presented in Eq. (2).

$$
F(t)=P\left[1+\sum \alpha_{i} \cos \left(2 \pi i f_{s} t+\Phi_{\mathrm{i}}\right)\right]
$$

Where:

$P$ : person' weight;

$\alpha_{i}$ : dynamic coefficient for the harmonic force;

$i$ : harmonic multiple $(i=1,2,3, \ldots, n)$;

$f_{s}$ : activity step frequency (dancing, jumping, aerobics or walking);

$t:$ time;

$\Phi_{i}$ : harmonic phase angel

Unlike the previous load model, this load was composed of a static parcel and a combination of four time-dependent repeated loads presented by Fourier series. Four harmonics (see Table 1) were adopted to produce the second dynamic load model. Considering a panel the same as the 
discussed panel in the previous load model with the FNF of equal to $8.359 \mathrm{~Hz}$, the fourth harmonic with a step frequency of $2.0897 \mathrm{~Hz}(4 \times 2.0897 \mathrm{~Hz}=8.359 \mathrm{~Hz})$ was the walking load resonant harmonic. Table 1 shows the dynamic coefficients and phase angles for each harmonic which were used to produce second dynamic load model, as illustrated in Fig. 4.

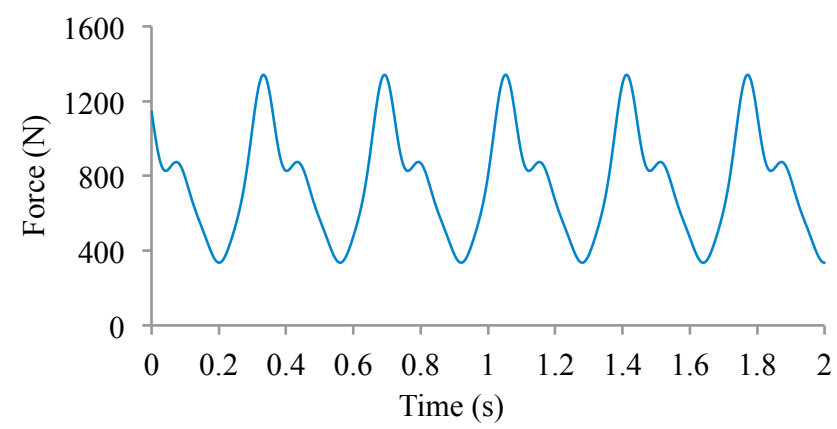

Figure 4 Second and third load models for PN8.

\subsection{Third load model}

The mathematical function of the third load model is similar to the second one, presented in Eq. (2). Similar to the previous load model, the fourth harmonic with a step frequency of $2.0897 \mathrm{~Hz}$ was the resonant harmonic of human walking load (see Table 1). The third load model is more pragmatic than the last two kinds of the load models, as the position of this load is changed across the singular location of the floor system (see Fig. 5).

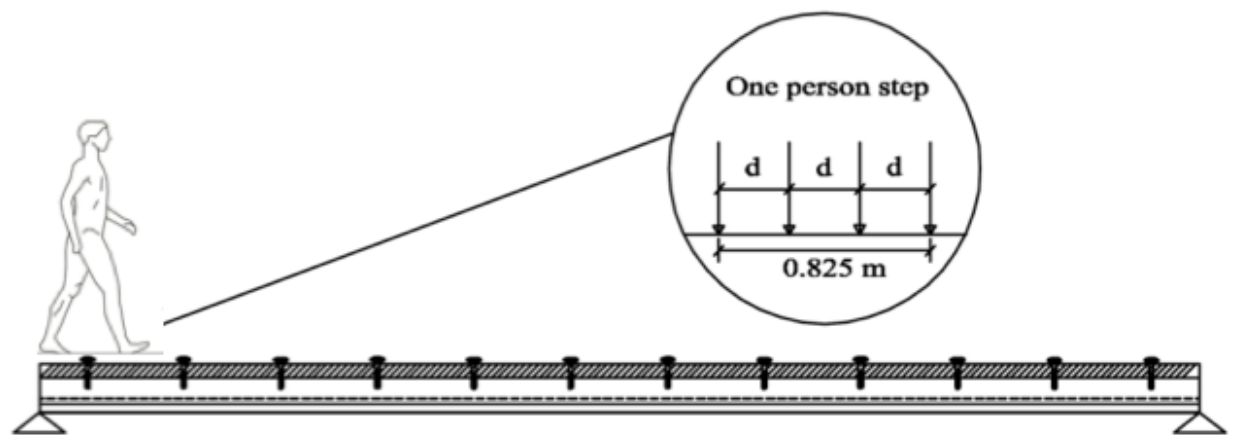

Figure 5 Person walking on the PSSDB floor panel.

Study of some other parameters related to the step frequency such as step distance and speed of walking, presented in Table 2, is necessary in this kind of load. Also, finite element mesh should be very refined in this dynamic load model. The contact time of applying the dynamic load with floor was calculated based on the step distance and step frequency (see Table 2). 
In this case, the subsequent scheme was followed: In a panel the same as the panel in the previous load models, and according to Table 1, the step frequency was equal to $2.0897 \mathrm{~Hz}$ when the fourth harmonic was as resonant harmonic. Therefore, in accordance with Table 2, the step distance was equal to $0.825 \mathrm{~m}$ (see Fig. 5).

Table 2 Person walking characteristics (Mello et al. 2008).

\begin{tabular}{cccc}
\hline Activity & $\begin{array}{c}\text { Velocity } \\
(\mathrm{m} / \mathrm{s})\end{array}$ & $\begin{array}{c}\text { Step disance } \\
(\mathrm{m})\end{array}$ & $\begin{array}{c}\text { Step frequency } \\
(\mathrm{Hz})\end{array}$ \\
\hline Slow walking & 1.1 & 0.6 & 1.7 \\
Normal wal- & 1.5 & 0.75 & 2.0 \\
king & 2.2 & 1.0 & 2.3 \\
Fast walking & & & \\
\hline
\end{tabular}

The step period which corresponds with the step distance of $0.825 \mathrm{~m}$ is equal to $1 / f=$ $1 / 2.0879=0.4785 \mathrm{~s}$ ( see Table 2). As it is shown in Fig. 5, four forces were considered representing one human step which each of the forces as P1, P2, P3, and P4 was applied on the floor during 0.4785 (contact time) $/ 3=0.16 \mathrm{~s}$. The dynamic forces of $\mathrm{P} 1, \mathrm{P} 2, \mathrm{P} 3$, and $\mathrm{P} 4$ were not applied together at the same time. First, the load of P1 was applied on the floor according to Eq. (2) for $0.16 \mathrm{~s}$. At the end of this time period, the load of P1 became zero and the load of P2 was applied for $0.16 \mathrm{~s}$. The other loads of the first person step, P3 and P4, were applied in the same procedure described previously. After $0.4785 \mathrm{~s}$, the first person step finished and the second person step started and the load of P1 of the second step was equal to the load of P4 of the first step. According to the explained method, the process continued repeatedly till all dynamic forces applied along the considered path (see Fig. 11) on the floor.

\subsection{Fourth load model}

The fourth dynamic load model representing human walking load is investigated with the same procedure considered in the third one. The principal difference between the third and fourth load models was the consideration of the human heel effect in the fourth load which was ignored in the third load model. The human heel effect was shown to be an effective parameter on the increase of the load by comparison of the third and fourth load models. According to Mello et al. [7] Varelo (2004) proposed the mathematical functions of this load model as Eqs. (3)-(6). 


$$
\begin{cases}\left(\frac{f(t)=}{0.04 T_{p}}\right) t+P & \text { if } 0 \leq t<0.04 T_{p} \\ f_{m i} F_{m}\left[\frac{C_{1}\left(t-0.04 T_{p}\right)}{0.02 T_{p}}+1\right] & \text { if } 0.04 T_{p} \leq t<0.06 T_{p} \\ F_{m} & \text { if } 0.06 T_{p} \leq t<0.15 T_{p} \\ P\left[1+\sum_{i=1}^{n h} \alpha_{i} \sin \left(2 \pi i f_{s}\left(t+0.1 T_{p}\right)+\Phi_{\mathrm{i}}\right)\right] & \text { if } 0.15 T_{p} \leq t<0.90 T_{p} \\ 10\left(P-C_{2}\right) \cdot\left(\frac{t}{T_{P}}-1\right)+P & \text { if } 0.90 T_{p} \leq t<T_{p}\end{cases}
$$

$F_{m}$ : maximum Fourier series value, given by Eq. (4);

$f_{m i}$ : heel-impact factor;

$T_{p}$ : step period;

$C_{1}$ : coefficients given by Eq. (5);

$C_{2}$ : coefficients given by Eq. (6).

$$
\begin{gathered}
F_{m}=P\left(1+\sum_{i=1}^{n h} \alpha_{i}\right) \\
C_{1}=\left(\frac{1}{f_{m i}}-1\right) \\
C_{2}= \begin{cases}P\left(1-\alpha_{2}\right), & \text { se } n h=3 \\
P\left(1-\alpha_{2}+\alpha_{4}\right), & \text { se } n h=4\end{cases}
\end{gathered}
$$

Mello et al. [7] reported that Varela (2004) and Ohlsson (1982) stated the impact factor varies person-to-person. In this study, the impact factor was adopted equal to $1.12\left(f_{m i}=1.12([7])\right)$. Fig. 6 illustrates the dynamic load model of a panel which presented in the previous load models with the FNF of $8.359 \mathrm{~Hz}$ based on Eqs. (3)-(6). 


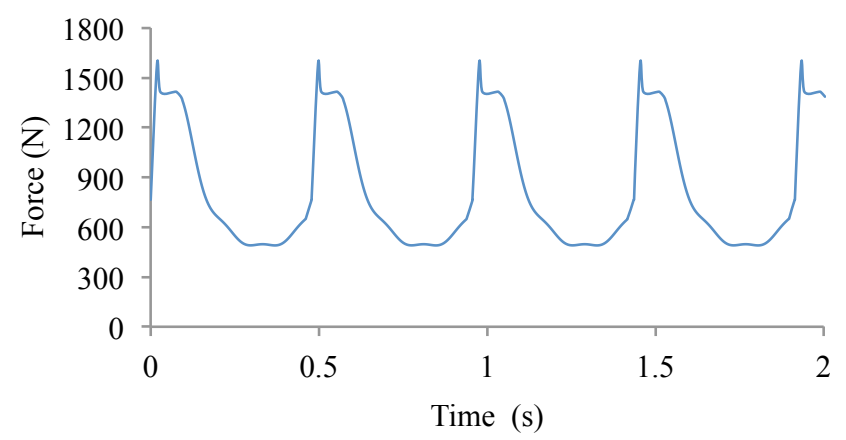

Figure 6 Fourth load model for PN8.

\section{STRUCTURAL MODEL}

Peva45 is available in the local market by the width of $795 \mathrm{~mm}$ and maximum length of $15 \mathrm{~m}$. Also, maximum length and width of plywood are $2400 \mathrm{~mm}$ and $1200 \mathrm{~mm}$, respectively. Therefore, to prepare the PSSDB panels with practical dimensions with sizes greater than the size of Peva45 or plywood, some pieces of Peva45 and plywood should be used together. In the current study, the panels are consisted of four (4) pieces of Peva45 and eight (8) pieces of plywood. Fig. 7 shows the section of the studied panels. The connection between two adjacent Peva45 side by side panels (detail A) was represented by a typical lap joint idea as shown in Fig. 8. Wright and Evans [24] presented the connectivity characteristics of such joint. As can be seen in Fig. 8, nodes I(2) and $\mathrm{J}(2)$ are connected to nodes $\mathrm{I}(3)$ and $\mathrm{J}(3)$ respectively, assuming complete freedom in the longitudinal and rotational directions whilst assumed to have complete connection in the vertical and lateral directions [24].

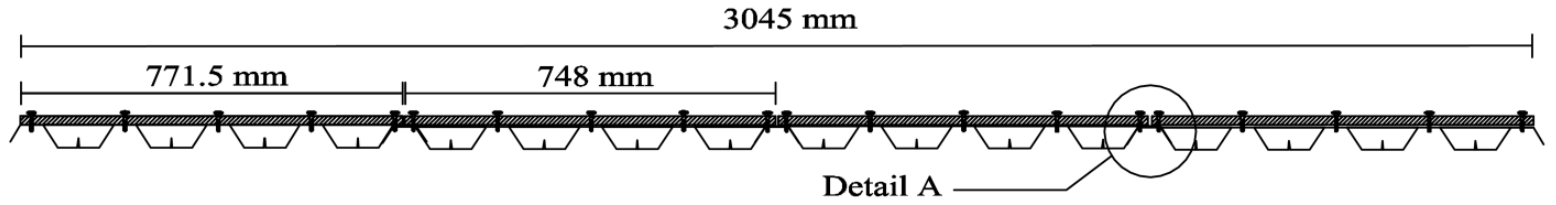

Figure 7 The section of studied panels.

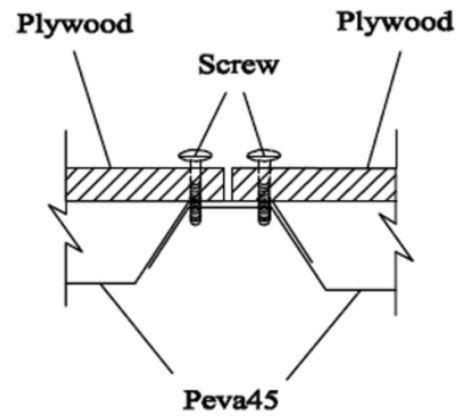

(a)

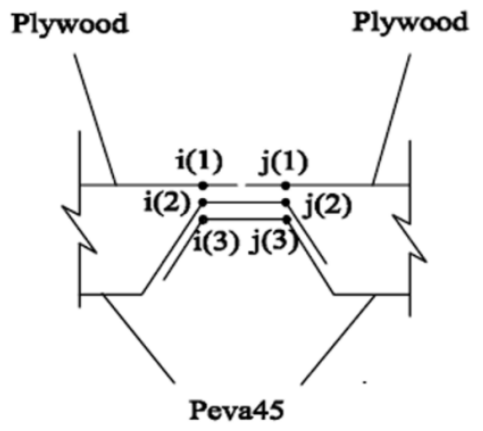

(b)

Figure 8 Detail A: (a) Constructional model (b) Analytical model. 
In this study and according to the steel construction institute (SCI-P354 2007) [25], damping ratios were adopted by $1.1 \%, 3 \%$, and $4.5 \%$ in order to consider different situations of the floor during the lifetime of its service (see Table 3 ).

Table 3 Proposed damping ratios by SCI-P354 for various floor types (SCI-P354 2007).

\begin{tabular}{ll}
\hline$\zeta(\%)$ & \multicolumn{1}{c}{ Floor finishes } \\
\hline 0.5 & For fully welded steel structures, e.g. staircases \\
1.1 & For completely bare floors or floors where only a small amount of furnishings are present \\
3.0 & For fully fitted out and furnished floors in normal use \\
4.5 & For a floor where the designer is confident that partitions will be appropriately located \\
& to interrupt the relevant mode (s) of vibration (i.e. the partition lines are perpendicular \\
& to the main vibrating elements of the critical mode shape) \\
\hline
\end{tabular}

The PSSDB control panel (PN1 (see Table 4)) adopted $0.8 \mathrm{~mm}$ thick Peva45 as PSS, $18 \mathrm{~mm}$ thick plywood as DB, DS-FH 432 self-drilling and self-tapping screw at $200 \mathrm{~mm}$ screw spacing as the connectors. Twelve (12) PSSDB panels have been developed with various supports as shown in Fig. 9. The characteristics of these panels are summarized in Table 4.

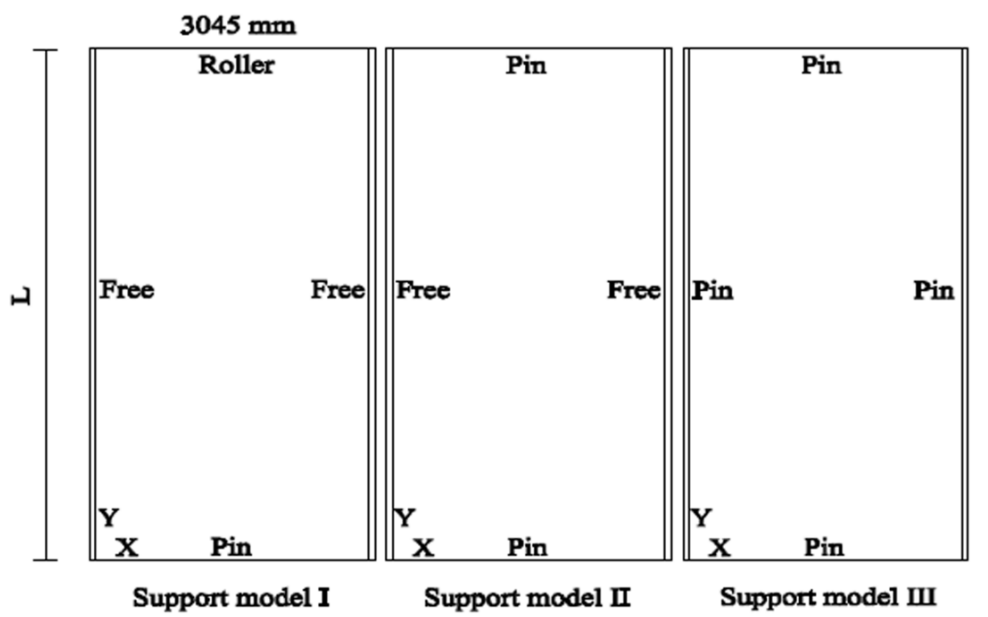

Figure 9 Considered supports in the study. 
Table 4 Characteristics of the studied panels.

\begin{tabular}{ccccccc}
\hline $\begin{array}{c}\text { Panel } \\
\text { No. } \\
(\mathrm{PN})\end{array}$ & L(m) & $\begin{array}{c}\text { Support } \\
\text { type } \\
\text { (see fig.9) }\end{array}$ & $\begin{array}{c}\text { Thickness } \\
\text { of PSS } \\
(\mathrm{mm})\end{array}$ & $\begin{array}{c}\text { Thickness } \\
\text { of DB } \\
(\mathrm{mm})\end{array}$ & $\begin{array}{c}\text { Screw } \\
\text { spacing } \\
(\mathrm{mm})\end{array}$ & $\begin{array}{c}\text { Damping } \\
\text { ratio } \%)\end{array}$ \\
\hline 1 & 4200 & I & 0.8 & 18 & 200 & 1.1 \\
2 & 4200 & I & 0.8 & 18 & 200 & 3.0 \\
3 & 4200 & I & 0.8 & 18 & 200 & 4.5 \\
4 & 4200 & I & 0.8 & 25 & 200 & 1.1 \\
5 & 4200 & I & 1.0 & 18 & 200 & 1.1 \\
6 & 4200 & I & 0.8 & 18 & 100 & 1.1 \\
7 & 4200 & II & 0.8 & 18 & 200 & 1.1 \\
8 & 4200 & III & 0.8 & 18 & 200 & 1.1 \\
9 & 4200 & III & 0.8 & 18 & 200 & 3.0 \\
10 & 4200 & III & 0.8 & 18 & 200 & 4.5 \\
11 & 3600 & I & 0.8 & 18 & 200 & 1.1 \\
12 & 4800 & I & 0.8 & 18 & 200 & 1.1 \\
\hline
\end{tabular}

The dynamic Young's modulus of materials was used in this study. According to AISC [6], the dynamic Young's modulus for steel can be chosen similar to its static value (BS 5950 Part-4 [26]), i.e. $2.10 \times 10^{5} \mathrm{MPa}$ for Peva45. Stalnaker and Harris [27] stated that the property of plywood is mostly isotropic because of its manufacturing process. Also, Ahmed [28] declared that although dry boards may be found as isotropic or orthotropic in nature, they can be modeled as isotropic plates without any difficulties. With the consideration of isotropic sheeting, the static Young's modulus of plywood which is available in the local market adopted as $7164 \mathrm{MPa}$ [29] in this study. Nevertheless, the dynamic value was chosen $10 \%$ greater than the static value according to Bos and Bos Casagrande [30].

The stiffness of screws which are connections between Peva45 and plywood was obtained by push-out tests. The stiffness of shear connectors is needed in the finite element analysis. Nordin et al. [31] performed a study to identify the stiffness of screws between Peva45-Cemboard, Cemboard-Timber, and Peva45-Plywood. It was found that the shear connection stiffness between Peva45 and plywood was $610 \mathrm{~N} / \mathrm{mm}$ [31]. This value was represented instead of the connections between $\mathrm{I}(1)$ and $\mathrm{J}(1)$ respectively to $\mathrm{I}(2)$ and $\mathrm{J}(2)$ (see Fig. 8). The density of Peva45 and plywood were adopted as $7850 \mathrm{~kg} / \mathrm{m}^{3}$ and $600 \mathrm{~kg} / \mathrm{m}^{3}$, respectively.

\section{COMPUTATIONAL MODEL}

The FEM presents a more accurate dynamic response, especially for structures with involved geometry. Using this method is enhanced because it can reduce the cost of computing functions [17]. The logical estimation on vibration of composite floors under walking load is a complicated work because of complexity in the geometry of structures, variety of material properties in different structural components, and the nature of walking load as a continuous and transient load. It has been known that using finite element method can cover and solve the mentioned tasks foremost [2]. Therefore, the FEM was used in this study to evaluate the dynamic response of the PSSDB system under human walking load.

Developed finite element models were simulated by the use of refined mesh in the ANSYS program [32]. In the studied system, the PSS and DB were made of SHELL281 element as a suitable 
element for analyzing thin to moderately-thick shell structures. In addition, the self-drilling and self-tapping screws were represented by COMBIN14 element as connection between Peva45 and plywood.

\section{DYNAMIC ANALYSIS OF THE STUDIED PANELS}

To determine the dynamic responses of the PSSDB composite panels, a linear time-domain analysis was performed [33]. The dynamic responses of the studied panels were determined from a vast parametric analysis performed via finite element ANSYS program [32]. The results were natural frequencies, displacements, velocities, and accelerations.

The main goal of this study was to evaluate vibration serviceability of the PSSDB composite panels under human walking load. For this purpose, the maximum acceleration of the panels was determined under the four dynamic load models described previously. Then, the obtained accelerations were compared with the ISO Standard [5].

\subsection{Natural frequencies and mode vibrations of studied panels}

Gandomkar et al. [21] carried out a wide experimental and numerical study on the natural frequencies of the PSSDB system. The numerical study performed by FEM presented accurate results compared with the corresponding experimental results. In the present study, developed finite element models which were verified by the literature [21] were used to determine the natural frequencies of the studied panels, as summarized in Table 5.

Table 5 First six natural frequencies of the studied panels.

\begin{tabular}{ccccccc}
\hline $\begin{array}{c}\text { Panel No. } \\
(\mathrm{PN})\end{array}$ & $\mathrm{f}_{01}(\mathrm{~Hz})$ & $\mathrm{f}_{02}(\mathrm{~Hz})$ & $\mathrm{f}_{03}(\mathrm{~Hz})$ & $\mathrm{f}_{04}(\mathrm{~Hz})$ & $\mathrm{f}_{05}(\mathrm{~Hz})$ & $\mathrm{f}_{06}(\mathrm{~Hz})$ \\
\hline $1,2,3$ & 5.863 & 6.364 & 8.115 & 10.810 & 13.053 & 22.646 \\
4 & 5.491 & 6.356 & 8.878 & 12.445 & 15.393 & 21.570 \\
5 & 6.150 & 6.609 & 8.287 & 10.955 & 10.235 & 23.694 \\
6 & 6.128 & 6.794 & 9.113 & 12.369 & 14.964 & 24.145 \\
7 & 7.786 & 8.200 & 9.741 & 12.321 & 14.576 & 23.190 \\
$8,9,10$ & 8.359 & 9.999 & 12.834 & 24.625 & 27.744 & 29.222 \\
11 & 7.978 & 8.441 & 10.148 & 12.935 & 15.367 & 29.371 \\
12 & 4.514 & 5.041 & 6.786 & 9.359 & 11.406 & 17.985 \\
\hline
\end{tabular}

The results of Table 5 illustrate that enhancing the thickness of plywood and Peva45 reduced and increased the FNF of the system, respectively. Therefore, it can be seen that the obtained results uncover the effect of the mass and stiffness of Peva45 and plywood on the FNF of the system. The PSSDB with screw spacing of equal to $100 \mathrm{~mm}$ is stiffer than the PSSDB with that of $200 \mathrm{~mm}$ [34]. It was shown that decreasing the screw spacing increased the FNF of the panel. Control of sliding parallel with the strong direction of the PSS and using four-sided support instead of two sided support (perpendicular to the strong direction of the PSS) can significantly 
increase the FNF of the system. Changing the panel span can also change the FNF of the panel. The FNF of the studied panels had two properties. First, all were smaller than $10 \mathrm{~Hz}$; therefore, they were in the category of LFF. Second, all were greater than $3 \mathrm{~Hz}$ as the minimum limitation of FNF for floors proposed by the SCI - P354 [25]. First six vibration modes of the PN8 are shown in Fig. 10. This figure helps structural designer to decide about situation of partitions constructed on the panel.

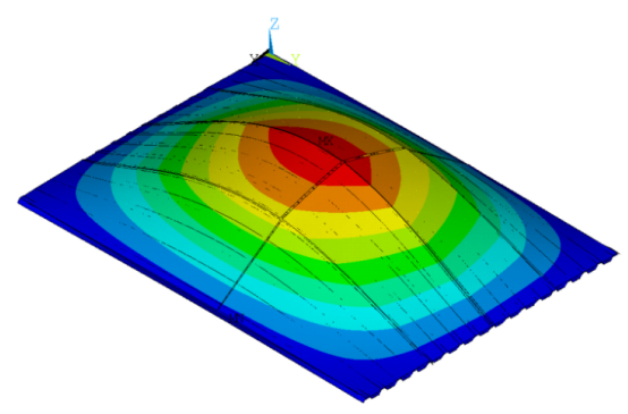

(a) Mode shape associated to the first natural frequency: $\mathrm{f}_{01}=8.359 \mathrm{~Hz}$

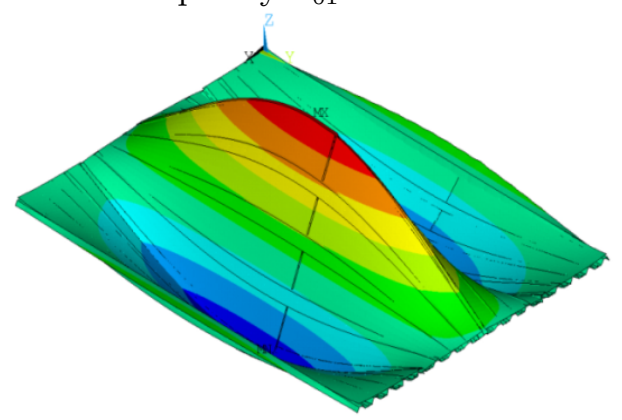

(c) Mode shape associated to the third natural frequency: $\mathrm{f}_{03}=12.834 \mathrm{~Hz}$

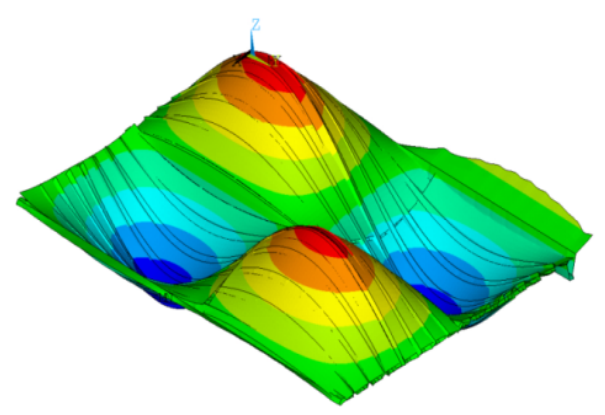

(e) Mode shape associated to the fifth natural frequency: $\mathrm{f}_{05}=27.744 \mathrm{~Hz}$

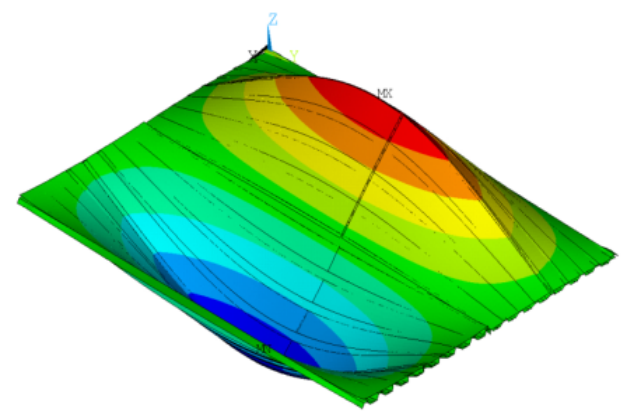

(a) Mode shape associated to the second natural frequency: $\mathrm{f}_{02}=9.999 \mathrm{~Hz}$

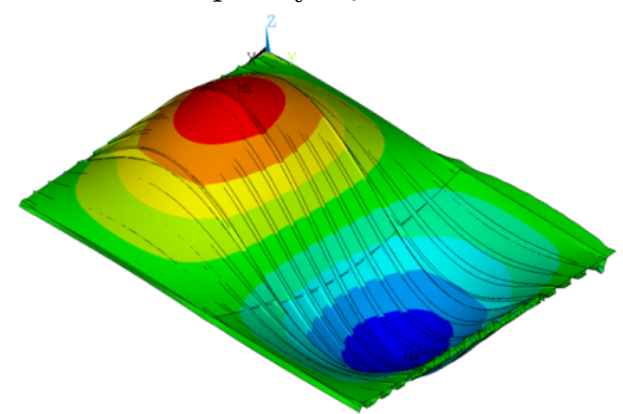

(d) Mode shape associated to the fourth natural frequency: $\mathrm{f}_{04}=24.625 \mathrm{~Hz}$

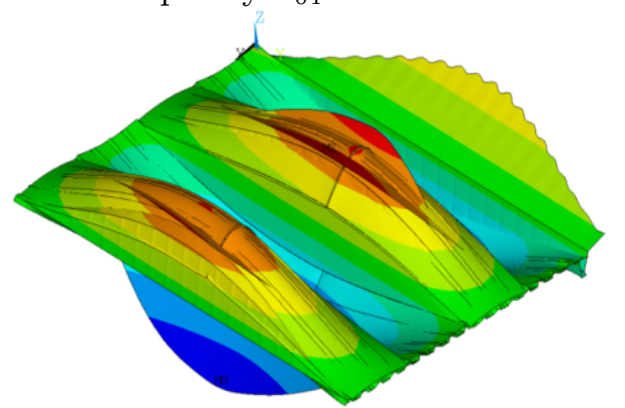

(f) Mode shape associated to the sixth natural frequency: $\mathrm{f}_{06}=29.222 \mathrm{~Hz}$

Figure 10 Floor vibration modes of model number 8. 


\subsection{Peak acceleration of studied panels}

The peak accelerations of the panels were determined by the dynamic analysis of the developed finite element models. Person walking across the panel was considered in the third and fourth dynamic load models. Therefore, the paths of walking should be defined. The peak accelerations of all models were obtained for path 1 (see Fig. 11) under three different support models (see Fig. 9). Also, the peak accelerations of PN2, PN7, and PN9 were determined where path 2 (see Fig. 11) was selected for walking. Table 6 indicates the peak accelerations of the PSSDB panels under the four previously described loads. This table also presents the limit of peak acceleration recommended by the ISO 2631-2 [5] for residences and offices (see Fig. 1).

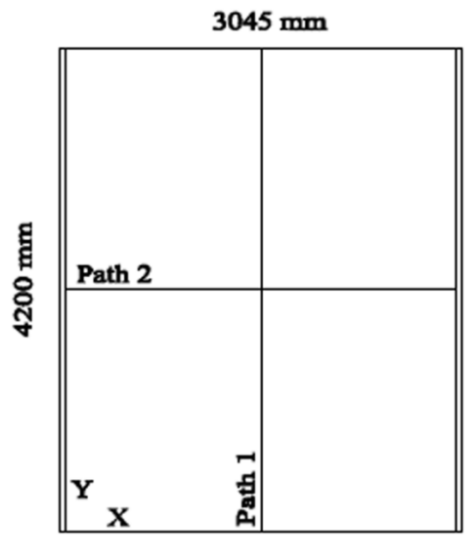

Figure 11 Layout of paths.

Table 6 Peak accelerations of the studied panels at resonance.

\begin{tabular}{|c|c|c|c|c|c|c|c|}
\hline \multirow[t]{2}{*}{$\begin{array}{l}\text { Panel No. } \\
\text { (PN) }\end{array}$} & \multirow{2}{*}{$\begin{array}{c}\text { Load model } \\
\mathrm{I} \\
\left(\mathrm{m} / \mathrm{s}^{2}\right) \\
\end{array}$} & \multirow{2}{*}{$\begin{array}{c}\text { Load model } \\
\text { II } \\
\left(\mathrm{m} / \mathrm{s}^{2}\right) \\
\end{array}$} & \multicolumn{2}{|c|}{$\begin{array}{c}\text { Load model III } \\
\left(\mathrm{m} / \mathrm{s}^{2}\right)\end{array}$} & \multicolumn{2}{|c|}{$\begin{array}{c}\text { Load model IV } \\
\left(\mathrm{m} / \mathrm{s}^{2}\right)\end{array}$} & \multirow{2}{*}{$\begin{array}{c}\text { ISO 2631- } \\
\quad(1989) \\
\end{array}$} \\
\hline & & & Path 1 & Path 2 & Path 1 & Path 2 & \\
\hline 1 & 0.03969 & 0.04525 & 0.14237 & - & 0.18472 & - & \\
\hline 2 & 0.03354 & 0.04163 & 0.11435 & 0.10215 & 0.15030 & 0.12824 & \\
\hline 3 & 0.03098 & 0.03816 & 0.10074 & - & 0.13475 & - & \\
\hline 4 & 0.03119 & 0.04036 & 0.12694 & - & 0.16001 & - & \\
\hline 5 & 0.02917 & 0.03898 & 0.11693 & - & 0.15621 & - & \\
\hline 6 & 0.03247 & 0.04186 & 0.13321 & - & 0.17104 & - & \\
\hline 7 & 0.03645 & 0.04639 & 0.14676 & 0.11745 & 0.18806 & 0.16314 & 0.04903 \\
\hline 8 & 0.03782 & 0.04886 & 0.15638 & - & 0.19303 & - & \\
\hline 9 & 0.03268 & 0.04223 & 0.13025 & 0.14957 & 0.16096 & 0.17504 & \\
\hline 10 & 0.02948 & 0.03851 & 0.11019 & - & 0.14477 & - & \\
\hline 11 & 0.02713 & 0.03948 & 0.12147 & - & 0.16662 & - & \\
\hline 12 & 0.04308 & 0.05852 & 0.17353 & - & 0.20123 & - & \\
\hline
\end{tabular}


In accordance with Table 6 , the peak accelerations of the studied panels were obtained under the second load model which showed to be greater than those corresponding peak accelerations evaluated under the first load model. This point revealed that considering four harmonics in the dynamic load is a very important issue in the dynamic responses of the floor and showed a considerable effect on the increase of the peak acceleration. As it is shown in Table 6, when the third and fourth load models applied on the studied panels the peak accelerations were higher than those of the applied first and second load models. This fact was highlighted when the position of the dynamic load changed across the individual direction, the dynamic response of the panels increased. Mello et al. [7] also focused on this point and stated that this is a substantial increase in the structure. The peak acceleration of the panels under the fourth load model was evaluated higher than those under the third load model. On the other hand, the scheme of loading on the panels in the third and fourth load models was the same as each other. Therefore, this increase should be caused by the heel impact factor $\left(f_{m i}=1.12\right)$ used in the fourth load model.

According to the comparison of limit states of the ISO Standard [5] with the peak accelerations of the panels produced by the first load model, all studied panels did not have any problems regarding the human comfort. By comparing the results of PN1, PN7, and PN8, an unknown interaction was revealed between the dynamic load model with different parameters such as support conditions and dynamic characteristics of the panels which made an unknown phenomenon in the dynamic response of the panels. It should be noted that the harmonic of resonant in PN1was the third harmonic; therefore, the dynamic coefficient of the load was 0.1. However, the fourth harmonic was a resonant harmonic in PN7 and PN8, accordingly, the dynamic coefficient was 0.05. By investigation of the results of the second load model, all studied panels except the panel with $4.8 \mathrm{~m}$ length (PN12) did not show any problems related to the human comfort. On the other hand, by comparing the peak accelerations of the dynamic analysis of the panels under the third and fourth load models and recommendation of the ISO 2631-2 [5], it was revealed that all panels were not comfortable for human.

The results on path 1 also uncovered that the dynamic response of the panels is changed by changing the characteristics of the PSSDB panel. By increasing the thickness of plywood from 18 $\mathrm{mm}$ to $25 \mathrm{~mm}$ and Peva45 from $0.8 \mathrm{~mm}$ to $1.0 \mathrm{~mm}$, peak accelerations of the four load models were decreased by an average value of $14.11 \%$ and $18.42 \%$, respectively. Furthermore, by reducing the screw spacing from $200 \mathrm{~mm}$ to $100 \mathrm{~mm}$, the peak acceleration of the four load models was decreased by an average value of $9.88 \%$. The results also indicated when damping ratios were changed from $1.1 \%$ to $3 \%$ and $4.5 \%$, the peak accelerations of the PSSDB panels were respectively decreased by $15.45 \%$ and $23.48 \%$ for the panel with the support type of I (see Table 4 and Fig. 9) and respectively $15.12 \%$ and $24.44 \%$ for that with the support type of III (see Table 4 and Fig. 9). By comparing PN1 with PN12 and PN13 it was shown that the length of the panels had a direct effect on the peak acceleration of the panels, where the response enhanced and reduced respectively for the increase and decrease of the length of panels for all four load models. However, these results are not addressable, as according to results of Mello et al. [7], the peak accelerations are not attributed on the length of the panels.

By comparison of results of PN1 and PN7, it is demonstrated that control of sliding in support decreased the peak acceleration of the panel for the first load model. It may be due to the signifi-

Latin American Journal of Solids and Structures 10(2013) 1135 - 1154 
cant increase of the FNF of the panel, therefore, the dynamic coefficient changed from 0.1 to 0.05 . On the other hand, as stated in the first load model, only one harmonic considered depending on the FNF. Generally, the dynamic load applied on PN1 was higher than that on PN7. According to results tabulated in Table 6 , the mentioned issue was not shown to be effective when four harmonics considered in the dynamic load models (load models of II, III, and IV), even for PN8. The reason was about the complexity in the dynamic responses of the panels under interaction between supports and other substantial characteristics of structures.

Comparing peak accelerations of path 1 and path 2 in the panels shows different phenomena. The response of path 1 was greater than that of path 2 when only two sides of panels were supported. On the other hand, the response of path 2 was greater than that of path 1 when all four sides of panels were supported. The panels were not also comfortable for users, where walking performed across path 2 .

Comparing the results of this study and study of Gandomkar et al. [19] shows that the presence of concrete grade 30 can reduce the peak accelerations of PSSDB panels. These reductions were determined by an average on all the studied panels by $16.5 \%, 15.8 \%, 17.1 \%$, and $23.5 \%$ respectively for load models I, II, III, and IV. It can be expressed that the presence of concrete grade 30 can decrease the peak acceleration of the PSSDB system by an average value of $18.2 \%$.

\section{FINAL REMARKS}

This paper investigated the dynamic response of the PSSDB low frequency floors under human walking load to evaluate the vibration serviceability of the system. Four dynamic load models were used while the third and fourth load models were more pragmatic having two properties; changing load according to the individual position, and generating time function corresponding to the nature of human walking load. In the fourth load model, the effect of human heel impact was also considered.

The dynamic responses of the studied PSSDB panels were obtained in terms of the peak acceleration and compared to the proposed limiting value by the ISO 2631-2 [5] where the panels used as residences and offices. The studied panels were showed to be comfortable when the first and second dynamic load models were applied on them, except the panel with $4.8 \mathrm{~m}$ length in the second load model. The position of loads was changed across the individual directions when the third and fourth dynamic load models were applied on the panels. For these two types of loads, two paths were selected to show the effect of direction of walking on the response of the panels. The peak accelerations of the studied panels under the third and fourth dynamic load models were determined higher than those of the first and second loads and also limiting value of the ISO 2631-2 [5]. Therefore, it was shown that the panels were not comfortable under the third and fourth load models. These results uncovered the fact that changing the position of load is an effective item in the response of the panels.

Increasing the thickness of the PSS and DB and decreasing screw spacing significantly reduced the peak acceleration of the system. Also, enhancing damping ratio of the PSSDB system can considerably decrease the peak acceleration of the system. These results can be useful to help designers to reduce the response of the floor by furniture and types of partitions (see Table 3). 
The increase and decrease of the length of the studied panels enhanced and reduced the peak acceleration of the panels, respectively.

The presence of concrete grade 30 can reduce peak acceleration of the PSSDB system by an average value of $18.2 \%$.

Acknowledgements Authors wish to thanks Mr. Alireza Bahrami, who contributed in language editing of this paper.

\section{References}

[1] A. Ebrahimpour, A. Hamam, R. L. Sack, and W. N. Patten. Measuring and modeling dynamic loads imposed by moving crowds. Journal of Structural Engineering, 122:1468-1474, 1996.

[2] Y. Chen. Finite element analysis for walking vibration problems for composite building floor using ADINA: modeling, simulation, and comparison. Computer and Structures, 72:109-126, 1999.

[3] B. Ellingwood and A. Tallin. Structural serviceability floor vibrations. Journal of Structural Engineering, 110:401-420, 1984.

[4] A. A. Al-Foqaha, F. C. William, and K. J. Fridly. Vibration design criterion for wood floors exposed to normal human activities. Journal of Structural Engineering, 125:1401-1406, 1999.

[5] International Standards Organization / ISO 2631-2. Evaluation of human exposure to whole-body vibration, part 2: Human exposure to continuous and shock-induced vibration in buildings (1-80 Hz), 1989.

[6] M. M. Murray, D. E. Allen, and E. E. Ungar. Floor vibration due to human activity. In $11^{\text {th }}$ Steel design guide series, American Institute of Steel Construction, Chicago, USA, 1997.

[7] A. V. A. Mello, J. G. C. da Silva, P. C. G. da S Vellasco, S. A. L. de Andrade, and L. R. O. de Lima. Dynamic analysis of composite systems made of concrete slabs and steel beams. Journal of Constructional Steel Research, 64:1142-1151, 2008

[8] S. Sandun De Silva and D. P. Thambiratnam. Dynamic characteristics of steel-deck composite floors under human-induced loads. Computers and Structures, 87:1067-1076, 2009.

[9] J. G. S. da Silva, P. C. G. da S Vellasco, S. A. L. de Andrade, F. J. da CP Soeiro, and R. N. Werneck. An evaluation of the dynamical performance of composite slabs. Computers and Structures, 81:1905-1913, 2003.

[10] J. G. C. da Silva, P. C. G. da S Vellasco, S. A. L. de Andrade, and L. R. O. de Lima. Dynamic response of composite steel deck floors. Latin American Journal of Solid and Structures, 3:163-178, 2006.

[11] E. El-Dardiry and T. Ji. Modeling of the dynamic behaviour of profiled composite floors. Engineering Structures, 28:567-79, 2005.

[12] M. S. Williams and P. Waldron. Evaluation of methods for predicting occupant-induced vibrations in concrete floors. The structural Engineer, 72:334-340, 1994.

Latin American Journal of Solids and Structures 10(2013) 1135 - 1154 
[13] I. Smith and Y. H. Chui. Design of lightweight wooden floors to avoid human discomfort. Canadian journal of Civil Engineering, 15:254-262, 1988.

[14] C. Q. Howard and C. H. Hansen, Vibration analysis of waffle floors. Computers and Structures, 81:15-26, 2003.

[15] R. O. Foschi, G. A. Neumann, F. Yao, and B. Folz. Floor vibration due to occupants and reliability-based design guidelines. Canadian Journal of Civil Engineering, 22:471-479, 1995.

[16] K. P. Osborne and B. R. Ellis. Vibration design and testing of a long-span lightweight floor. The Structural Engineer, 68:181-186, 1990.

[17] C. J. Middleton and J. W. W. Brownjohn. Response of high frequency floors: A literature review. Engineering Structures, 32(2):337-352, 2010.

[18] M. Willford, P. Young, and C. Field. Predicting footfall-induced vibration: Part I. Proceedings of the Institution of Civil Engineers, Structures and Buildings, 160(SB2):65-72, 2007.

[19] F. A. Gandomkar, W. H. Wan Badaruzzaman, and S. A. Osman. Dynamic response of low frequency Profiled Steel Sheet Dry Board with Concrete infill (PSSDBC) floor system under human walking load. Latin American Journal of Solids and Structures, 9:21-41, 2012.

[20] H. D. Wright, H. R. Evans, and C. A. Burt. Profiled steel sheet/dry boarding composite floors. The Structural Engineer, 67:114-121, 1989.

[21] F. A. Gandomkar, W. H. Wan Badaruzzaman, and S. A. Osman. The natural frequencies of composite Profiled Steel Sheet Dry Board with Concrete infill (PSSDBC) system. Latin American Journal of Solids and Structures, 8:351-372, 2011.

[22] B. Folz and R. O. Foschi. Coupled vibrational response of floor systems with occupants. Journal of Engineering Mechanics, 117:872-892, 1991.

[23] V. Racic, A. Pavic, and J. M. W. Brownjohn, Experimental identification and analytical modeling of human walking forces: Literature review. Journal of Sound and Vibration, 326:1-49, 2009.

[24] H. D. Wright and H. R. Evans. A folded plate method of analysis for profiled steel sheeting in composite floor construction. Thin-Walled Structures, 5:21-37, 1987.

[25] A. L. Smith, S. J. Hicks, and P. J. Devine. Design of floors for vibration: A new approach. The Steel Construction Institute (SCI-P354), Silwood Park, Ascot, Berkshire SL5 7QN, 2007.

[26] British Standards Institute. BS 5950: Part 1. Structural use of steelwork in building, Code of practice for design of composite slabs with profiled steel sheeting. UK, 1994.

[27] J. J. Stalnaker and C. E. Harris. Structural design in wood. Kluwer Academic Publishers, Massachusetts, USA, 1999.

[28] E. Ahmed. Behaviour of profiled steel sheet dry board folded plate structures. PhD thesis, Department of Civil \& structural Engineering, Universiti Kebangsaan Malaysia, Malaysia, 1999. 
[29] T. C. Yean. Load carrying capacity of dry floor panel system. M.Sc thesis, Faculty of Civil Engineering, Universiti Teknologi Malaysia, Malaysia, 2006.

[30] F. Bos and S. Bos Casagrande. On-line non-destructive evaluation and control of wood-based panels by vibration analysis. Journal of sound and vibration, 268:403-412, 2003.

[31] N. Nordin, W. H. Wan Badaruzzaman, and H. Awang. Connector stiffness of 'Peva-Cemboard' screwed connection in profiled steel sheet dry board (PSSDB) panel. Proceedings, In Fifth International Conference on Construction in $21^{\text {st }}$ Century (CITC-V) "Collaboration and Integration in Engineering Management and Technology", page 1476-1482, Istanbul, Turkey, 2009.

[32] Swanson Analysis System, Inc, Houston, PA. ANSYS - Version 11.0, 2007.

[33] R. W. Clough and J. Penzien. Dynamic of structures, McGraw-Hill, Inc, New York, USA, 2nd edition, 1993.

[34] W. H. Wan Badaruzzaman, M. F. M. Zain, A. M. Akhand and E. Ahmed. Dry board as load bearing element in the profiled steel sheet dry board floor panel system-structural performance and applications. Journal of Construction and Building Materials, 17(4):289-297, 2003. 